Our Nature (2012) 10: 258-268

\title{
Redescription of leaf miners (Agromyzidae) infesting pods of legumes from India and Nepal
}

\author{
Ram Bahadur Thapa \\ Department of Zoology, P.G. Campus, T.U., Biratnagar, Nepal \\ E-mail:niwaj@yahoo.com
}

\begin{abstract}
Two species of pod flies under the genus Melanagromyza Hendel were reared, redescribed and illustrated from India. These were Melanagromyza albisquama (Malloch) and Melanogromyza obtusa (Malloch). Melanagromyza albisquama (Malloch) was reared from seeds of Alysicarpus moniliform Dc., Alysicarpus rugosus Dc. (Linn.), Alysicarpus vaginalis (Linn.) Dc. and Desmodium gangeticum Dc. from Uttar Pradesh India. This is a first report from India. The second species reared, re-described and illustrated from India was Melanagromyza obtusa (Malloch) from pods of Cajanus cajan (Linn.) Millsp. and Flemingia congesta Roxb. Melanagromyza obtusa (Malloch) was also reared from pods of Cajanus cajan (Linn.) Millsp. from Biratnagar, eastern Nepal (Thapa, 2000) and this is the first report from Nepal. Variation within these species, were also described and illustrated, with genitalia preparation. The biology of albisquama (Malloch) has been clarified from India (Thapa, 1991). Descriptions and genitalia illustration broadly agreed with the illustrations figured by (Spencer, 1963, 1977). Variation within the species was also studied by the author (Thapa, 1991). Sehgal (1987) had also collected and reared large series of this species from several localities in Terai and Kumaon and Garhwal regions of Northern India on its widely cultivated host plants, Cajanus cajan (Linn.) Millsp. and an alternate wild host Flemingia congesta Roxb. Spencer (1973, 1977) has listed Cajanus indicus Spreng, Flemingia sp. and Phaseolus radiatus Linn. as leguminous hosts of this species. Six new species of other stem flies infesting mostly legumes were also discovered under the genus Melanagromyza (stem flies) from Pantnagar, northen India. These were: $M$. pathaki new; $M$.glycini new species; $M$. denticulata Willd. new species; $M$. pisiphaga new species; $M$. sehgali new species ; $M$.vicivora new species.New names have been proposed to them as per International rules of Zoological Nomenclature. Thapa (2012) has redescribed M. sojae (Zehntner) under Melanagromyza Hendel from India and Nepal.
\end{abstract}

Key words: Leaf miners, Pod flies, Diptera Agromyzidae, new species, leguminous host, India.

\section{Introduction}

Genus Melanagromyza Hendel, 1920:

Type of genus: Agromyza aeneoventris Fallen

Melanagromyza Hendel belongs to family Agromyzidae (Cyclorraphous, Diptera). This genus was erected by Hendel for black haltered species previously included in Agromyza. Normally there are only two pairs of post sutural dorsocentrals (dc), but a few species are known with three or even four, and in the United States two species namely M.trispinella, M. quadrisetosa were discovered in California having only a strong presutural dc. The costa invariably extends to $\mathrm{M}_{1+2}$ but in M.tamia and M. trispinosa and $M$. quadrisetusa where costa 
ends at vein $R_{4+5}$. Most species are entirely black, but in many the mesonotum or abdomen may be distinctly greenish or even bluish. Genitalia studied have shown that a number of species, which on the basis of external characters have been placed in Melanagromyza, correctly belong to Ophiomyia. This has been confirmed by biological and larval characters. The larvae of all known Melanagroyza species are internal feeders, mainly in the stem but also in the flower head, root, pods, and pupation occurs within the plant. Melanagromyza is one of the largest genera in the family, with over 300 described species. The genus is particularly well represented in the tropics and extends South to Chile, Australia and Newzealand (Spencer and Steyskal, 1986).

The members of Melanagromyza belong to Agromyzidae (Cyclorraphous, Diptera).Seventy five percent of this species under this family are leafminers and rest are either stem miners or podflies or make galls. Six new species of stem flies infesting legumes were also discovered under the genus. Melanagromyza (stem flies) from Pantnagar, northen India. These were: $M$. species new ex stem of Cassia sp. (proposed name $M$. pathaki new species); $M$. species new ex stems of Glycine max (Linn.) Merril. (proposed name $M$.glycini new species); $M$ - species new ex stems of Medicago denticulata wild. (proposed name $M$. denticulata Willd. New species); $M$. species new ex stems of Pisum sativum Linn. (proposed name $M$. pisiphaga new species); $M$. species new ex stems of Trifolium pratense Linn. (proposed name $M$. sehgali new species) and $M$. species new ex stems of Vicia faba Linn. (proposed name $M$. vicivora new species). New names have been proposed to them as per International rules of Zoological Nomenclature (Thapa, 1991, 1997a, 1997b, 2011, 2012). Thapa (2012) has redescribed M. sojae (Zehntner) under Melanagromyza Hendel from India and Nepal.

Leaf mines, stem mines, damaged seeds and process of genitalia preparations have been shown in Photographs 1, 2 and 3 (different species of leaf miners are associated with these damages).

\section{Materials and methods}

The research was carried out at Govind Ballabh Pant University of Agriculture and Technology, Pantnagar (Nainital) which is situated at $29^{\circ} \mathrm{N}$ latitude, $79.3^{\circ} \mathrm{E}$ longitude and at an altitude of 243.84 meters above sea level in Tarai region of the foot hills of Shivalik ranges of the Himalayan region having humid subtropical climate. The research was also continued at Biratnagar and Jhapa, eastern Nepal. Rearing of the flies was done in glass jars at room temperature or by transferring the puparia to the actual rearing container. All the major steps viz. dissection, transfer, washing, dehydration of abdomen, genitalia preparation and drawings were made under Binocular Microscope. Puparia of internal feeders were obtained by splitting the plant parts.

An attempt has been made to study all the existing species which could be reared during the survey. Apart from describing a new species, detailed morphological variations and differences in genitalia characters among the members within the species have also been carefully evaluated 
Ram Bahadur Thapa / Our Nature (2012) 10: 258-268
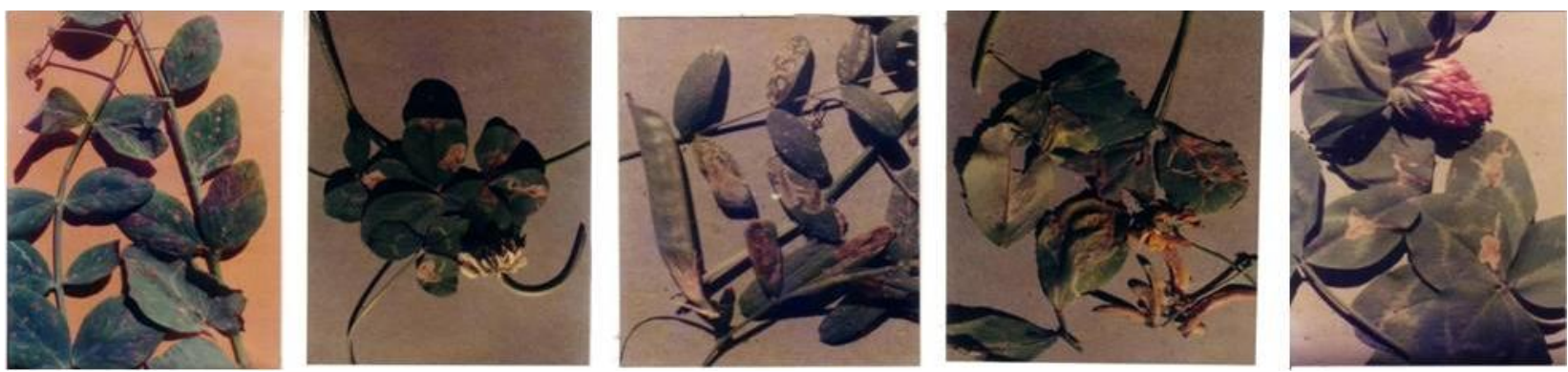

Photograph 1. Leaf mines
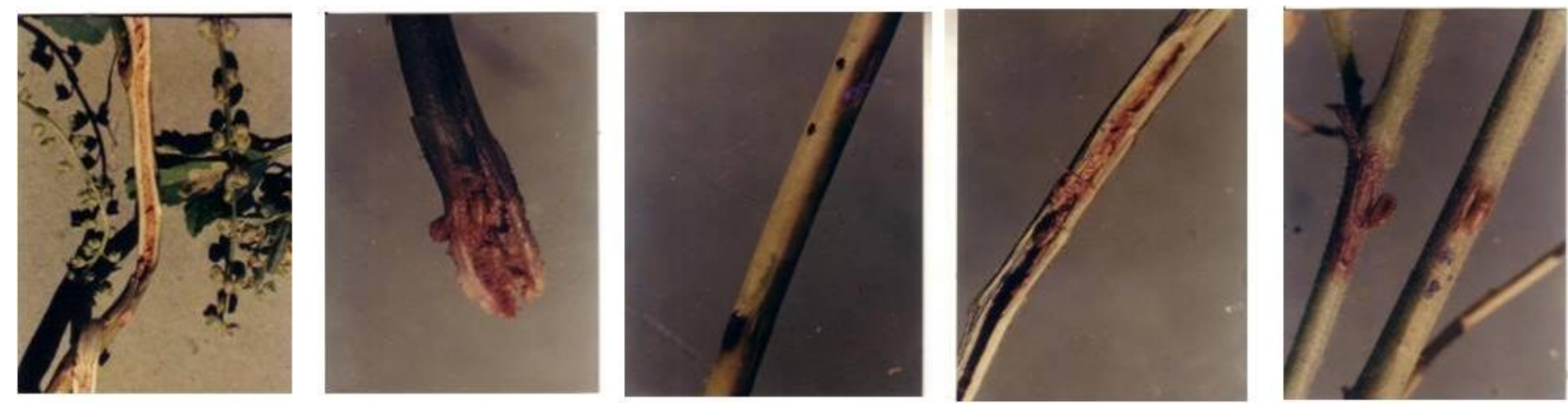

Photograph 2. Stem mines
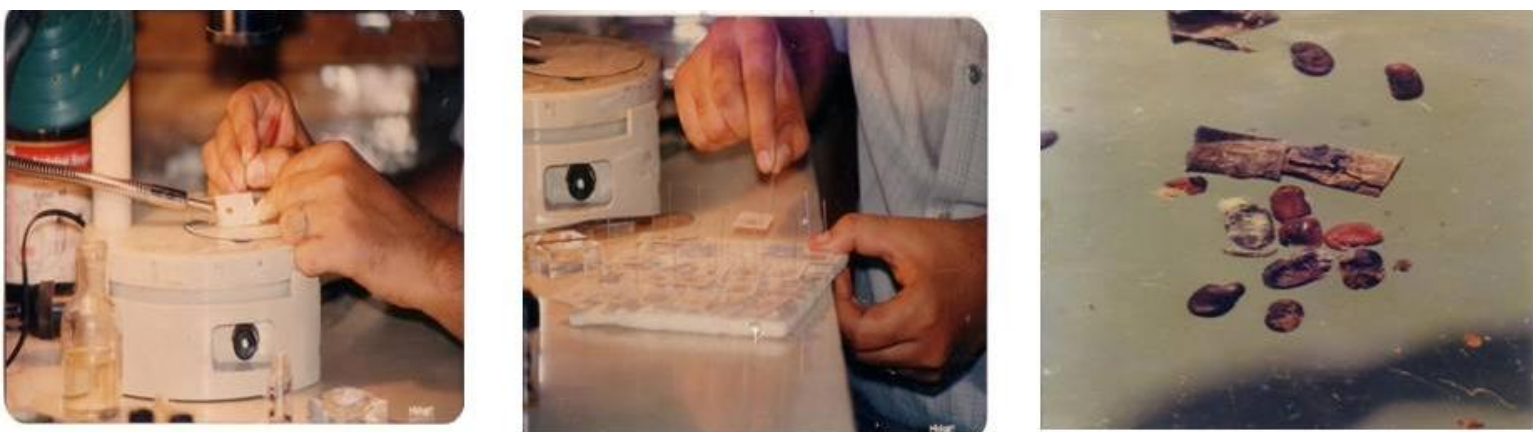

Photograph 3. (a) \& (b) showing genitalia slides (c) seeds damaged by Pods flies

and illustrated wherever felt necessary. Besides describing morphological and genitalia characters, their biology and host plants were also studied. In addition to redescribing 15 known species, 13 species are described and new names have been proposed to them as per International Rules of Zoological Nomenclatures.

Alysicarpus monolifer Dc.; Alysicarpus rugosus and Desmodium gangetium Dc. ; have been recorded as new hosts of 
Melanagromyza albisquama (Malloch). Biology of this fly has been clarified on these hosts from India. However these flies could not be reared in Biratnagar and Jhapa, Nepal during the study period (Thapa 1996, 2000; Poudyal 2003; Thapa 2005).

\section{Results and discussion}

The generic concept used in this study has been adopted from Frick (1952), Spencer (1973), Sehgal et al. (1980), Sehgal (1987), Spencer and Stayskal (1986), Saskawa (1960) and Griffiths (1972). An attempt has been made to study all the existing species which could be reared during survey. These species belong to different genera. Apart from describing a new species, detailed morphological variations and differences in genitalia characters among the members within the species have also been carefully evaluated and illustrated wherever felt necessary.

The characters of male genitalia especially the aedeagus complex have been used as far as possible in order to provide a basic for more accurate determination of species. However, the different members kept under one species had also shown minute differences in genitalic characters and on their some external morphology. Such difficulties came while dealing with the population of M. obtusa (Malloch).

Variations in ejaculatory apodeme; hypandrial apodeme; lobes, loops and bladder of distiphallus and sclerites of basiphallus were found to be differing between the members within the species. These differences may certainly play some role in reproductive isolation. But at this juncture the members which broadly agree in genitalia and morphological characters are grouped under the same species. In due time, the differences could be verified by interbreeding the different population.

In Agromyzidae, besides external morphological and genitalic characters, their biology and host plants are also equally important to identify a species.

Six new species of other stem flies infesting mostly legumes were also discovered under the genus Melanagromyza ( stem flies ) from Pantnagar, northen India. Melanagromyza albisquama (Malloch) and Melanagromyza obtusa (Malloch) are redescribed here.

Melanagromyza albisquama (Malloch) Agromyza (Melanagromyza) albisquama Malloch, 1927.

Melanagromyza albisquama Spencer, 1963. Melanagromyza leguminum Bezzi, 1928

(Synonymy established by Spencer, 1963)

Melanagromyza albisquama (Malloch) Thapa, 1991.

Comparison- The members of this species differ from those of obtusa (Malloch) in having smaller body size, wing length 1.57 $1.99 \mathrm{~mm}$ in males; eyes bare. The characters of genitalia are distinctive, basiphallus not greatly extended. Descriptions and genitalia illustration broadly agree with the illustrations figured by Spencer (1963, 1977). However, some remarkable differences were studied in the external morphological and genitalia characters. The population of albisquama (Malloch) in India differ from those described by Spencer (1963a, 1963b, 1977), in having gena 1/5.25-1/12 vertical height of eye, wing length $1.57-1.99 \mathrm{~mm}$ in male, the colour of squammae varies from whitish to brownish; arista long, pubescent; distiphallus fringed, 
revealed only at higher magnification, bladder inconspicuous with an additional sclerite in between ventral bladder and basiphallus.

Diagnostic characters- Small shining green species, with bare eyes, pubescent arista, gena 1/5.25-1/12 vertical height of eye; wing length $1.57-1.99 \mathrm{~mm}$ in male.

Description (plates 1 to 9) - Head. Width of frons $0.21-0.273 \mathrm{~mm}, 0.36$ equal to the width of eye at the level of front median ocellus, projected beyond eye in profile, in few specimens not projected; 2 ori, directed slightly upwards; 2 ors, directed slightly upwards; orbital setulae numerous, reclinate, in few specimens sparse eyes oval, bare; lunule absent; vibrissae numerous; eyes $0.42-0.54 \mathrm{~mm}, 1.33-1.91$ times higher than their lengths; gena $0.02-0.084 \mathrm{~mm}$, 1/5.25-1/12; ocellar triangle small; ocellar bristles strong; orbits normal, not projected in front of eye margin in profile; third antennal article round, in few specimens conspicuously elongated, with an angle in fews specimens much reduced spine anterodorsally directed, in few specimens spine minute, pubescence slight and normal; arista long pubescent.

Mesonotum- Two Dc; acr numerous.

Wing. Length 1.57- $1.99 \mathrm{~mm}$ in males; subcostal joining $\mathrm{R}_{1}$; costa extended to $\mathrm{M}_{1+2}$; costal segments 2-4 in the ratio 1: $0.26-0.26-1$ : 0.35 : 0.25 ; cross vein $\mathrm{m}-\mathrm{m}$ present; distal section of $\mathrm{M}_{3+4}$ 0.33- 0.85 times basal portin.

Male genitalia. Hypandrium Y shaped with broad side arms, apodeme variable short and pointed to long and broad .Epandrium. Cerci long without bristles or few weak bristles surstyli with spines. Aedeagus with basiphallus close to distiphallus complex, arms not much extended; distiphallus with a asymmetrical ventral bladder and terminal processes, numerous fringes are revealed at higher magnification on either side of the middle portion of distiphallus; bladder (in ventral view ) is surrounded by two characteristic processes; in some cases ventral bladder is inconspicuous. Shape and size of bladder, the processes surrounding it, and terminal projection varies; ejaculatory apodeme .Variable from minute to long without or with blades.

Colour- Frons blacks; orbits and ocellar triangle black; lunule black in fiew specimens bread from Alysicarpus spp. Whitish; antennae black; mesonotum black; scutellum black; halters black, in few specimens grey; legs black; squamae widely varies from whitish to brownish, margin and fringes white.

Biology- Larvae of this species mine the tiny seeds of various wild legumes of this region: Alysicarpus monolifer Dc; Alysicarpus vaginalis(Linn.)Dc.; Alysicarpus rugosus Dc and Desmodium gangeticum Dc.; during the months of April, August to January. Pupation takes place inside the seeds. Several expuparia have been collected by splitting the tiny seeds with the help of entomological pins under a binocular microscope. The expuparia are brownish and are very declicate. The peak period is in November. The incidence of this fly is very high; more than 100 flies were emerged in a day. Flies were reared even 
Ram Bahadur Thapa / Our Nature (2012) 10: 258-268
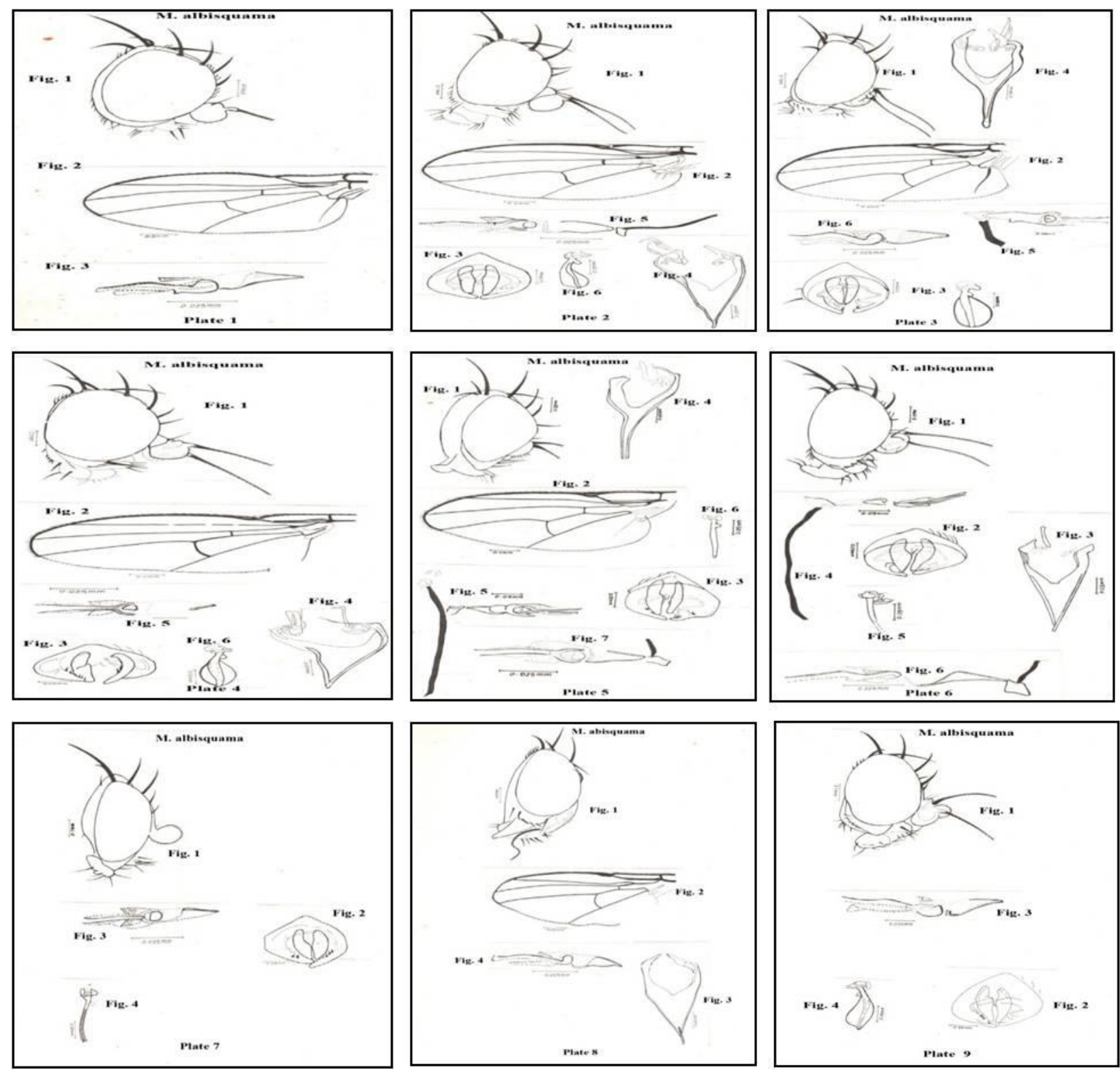

Plates 1-9. Plates showing head, wing and aedeagus complex (variations within the species have been shown). 
from very older seeds. The biology of albisquama (Malloch) has been clarified. Melanagromyza leguminum Fizi was bred from 'Pods of No. 51 C.T.W. In Mauritius albisquama ( as desmodi Spencer ) has been bred from pods of Desmodium frutescens walp. M. albisquama is wide spread in northen Australia. The synonymy with leguminum establishes that the host or hosts are in the papilionaceae but the actual species remain to be discovered. The closest relatives appear to be pseudograta sp. $\mathrm{n}$. (Spencer, 1963, 1977). Melanagromyza floridensis Spencer has been reared from Desmodium tortosum from N. America (Spencer and Steyskal, 1986). It is an entirely different species.

Geographical distribution- The member of this species are known from Cape Verde Is., South Africa, Ceylon, Indonesia, Australia, Caroline Is. (palau), Fiji. I examined the following material from Uttar Pradesh:

India. Uttar Pradesh: 1 o Pantnagar, District Nainnital, from seed of Alysicarpus rugosus Dc, Coll. 19.xi.87, emerged 27.xi.87; 3 ot ot same locality, from seeds of Alysicarpus vaginalis (Linn.) 3. xi. 87, emerged 5. Xi .87; 13 o $0^{*}$ same locality and host, Coll. 10. xi. 87, emerged 19-23. xi. 87; 6 o $0^{*}$ same locality and host, Coll. 10. xi. 87, emerged 6-14. Xii. 87; $70^{*} 0^{*}$ same locality and host, Coll. 4. i. 88, emerged 72-22.i.88; 2 o $0^{*}$ same locality from seeds of Desmodium gangeticum Dc., Coll. 30. x. 87, emerged 31.x.87; 19 o $0^{*}$ same locality and host, Coll. 30.x.87, emerged 1-3.x.87; 2 ot $0^{\star}$ same locality and host, Coll. 2. xi. 87, emerged 8-9. xi. 87; 41 $0^{\star} 0^{\star}$ same locality and host, Coll. 6.xi. 87, emerged 15-19. xi. 87; 1 o same locality and host, Coll. 10.xi.87, emerged 24.xi.87, 29 o ot $^{\text {s }}$ same locality and host, Coll. 18.xi. 87, emerged 20-23 xi. 87; 26 ơ ơsame locality and host, Coll. 21. xi. 87, emerged 25-30.xi.87; 20 o $0^{\text {t }}$ same locality and host, Coll. 21.xi.87, emerged 1-2.xii.87; 2 ○ $0^{\star}$ same locality and host, Coll. 10.i.88, emerged 18-23.i.88; 2 o* $0^{*}$ same locality and host, Coll. 6. iv. 88, emerged 1314.iv.88.

Redescription of Melanagromyza obtusa (Malloch):

Melanagromyza obtusa ( Malloch)

Agromyza obtusa Malloch, 1914.

Melanagromyza weberi de.Meijere, 1922.

Melanagromyza obtusa ( Malloch )

Henning, 1914 ;Spencer 1963, 1973.

Melananagromyza obtusa (Malloch) Thapa 1991.

Comparison- The members of this species differ from those of albisquama (Malloch) in having large body size, wing length 2.3$2.94 \mathrm{~mm}$ in males, lunule sunken, eyes pilose. The characters of genitalia are distinctive, basiphallus greatly extended. The aedeagus has also been illustrated by Spencer (1973, 1977) and Ipe (1967), Singh (1982) and Singh and Ipe (1973). Descriptions and genitalia illustrations of obtusa (Malloch) broadly agree with Spencer (1973, 1977). However, only few specimens studied agreed with gena: eye height ratio and colour of squammae; 1 specimen bread from Cajanus cajan Linn. has 3 ori and 2 ors frons quite relatively narrower in most of the specimens. 
External morphological characters of adult has also been compared with the description prepared by Singh and Ipe (1973).The colour of lunule in specimens I examined varied from whitish to black, gena relatively broader,squammae whitish to brownish, halters being completely black, eyes pilose.Description and genitalia preparations of $0^{*} 0^{*}$ reared from pods of Cajanus cajan (Linn.) Millsp. and an alternate host. Flemingia congesta Roxb. broadly agree. However, in Flemingia Pod fly, phallophore is with more prominent spines.

Diagnostic characters- Large shining species, wing length $2.3-2.94 \mathrm{~mm}$ in males; eyes pilose; gena $1 / 4-1 / 14.5$ vertical height of eye; lunule whitish ; colour of squamae slightly varies from whitish to brownish ; basiphallus with greatly extended side arms.

Description (plates10 to 15) -Head. Width of frons $0.29-0.39 \mathrm{~mm}$, relatively narrower, $0.56-1.1$ times the width of eye at the level of front median ocellus, slightly projected beyond eye in profile; 2 ori or 3 ori directed inwards or proclinate or slightly upwards; 2 ors strong directed upwards; orbital setulae numerous, reclinate, in 1 specimen in two rows apart from 1 or 2 hairs infront proclinate; eyes oval ; pilose; lunule broad and semicircular, sunken in few specimens; antennal bases approximate, well separated in 1 specimen; fascial keel narrow; eyes $0.52-0.73 \mathrm{~mm}, 1.31-1.70$ (in 2 specimens 1.82- 2.5) times higher than their lengths; gena 0.04 to $0.126 \mathrm{~mm}, 1 / 4.16-1 / 14.5$ vertical height of eye; ocellar triangle small, ocellar bristles strong; orbits normal raised from the plane of frons, not projected infront of eye margin in profile; third antennal article round, with an angle, in 1 specimen much reduced and without an angle ; spine strong or weak, arista long, pubescent.

Mesonotum - Two dc, acr numerous.

Wing. Length $2.3-2.94 \mathrm{~mm}$ in males; subcosta joining $\mathrm{R}_{1}$; costa extended to $\mathrm{M}_{1+2}$; costal segments $2-4$ in the ratio 1: 0.28 : 0.2 - 1: 0.32: 0.27; cross vein m-m present; distal section of $\mathrm{M}_{3+4} 0.47-0.58$ times basal portion; Male genitalia. Hypandrium Y shaped, with broad side arms, apodeme long;.Epandrium . Cerci long with bristles, surstyli with numerous spines. Aedeagus. Basiphallus with greatly extended side arms, encircles the distiphallus complex , appears entering inside distiphallus complex, its terminal portion gradually narrows, a characteristic minute process present at the base of bladder is inconspicuous. The loop above mesophallus is more broader. The outer phallophore in the population bred from Flemingia congesta Roxb. is with more prominent spines. A characterstic, less sclerotized bulb is present above basiphallus bred from Flemingia. The characteristic line which runs across the middle of distiphallus from left to right is broader. Ejaculatory apodemes variable, long, broad, blades, extended bulb large, well sclerotised.

Biology: Larvae of this species mines the seeds, pupation takes place in the same pod. Adult flies were reared from pods of Cajanus cajan (Linn.) Millsp. and Flemingia congesta Roxb. during the months of November, December and January. Sehgal (1987) has collected and reared long series of this species from 

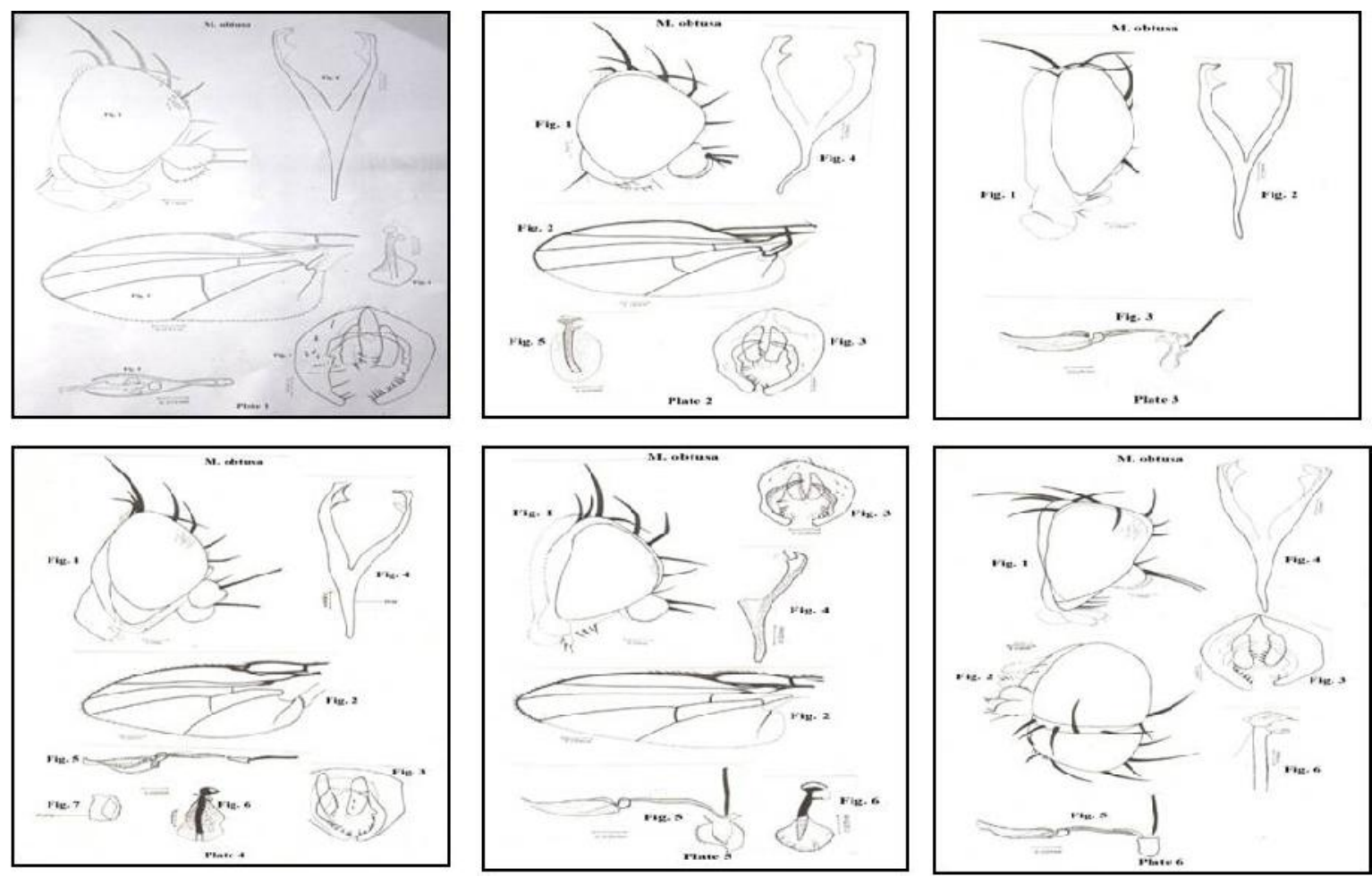

Plates 10-15. Plates showing head, wing and aedeagus complex complex (variations within the species have been shown).

several localities in the Tarai and Kumaon and Garhwal regions of northern India on its widely cultivated host plants, Cajanus cajan (Linn.) Millsp. and an alternate wild host Flemingia congesta Roxb. Sehgal (1965) had reared this species from Flemingia $=$ Moghania ) macrophylla (Wild), at Namkum (Rachi). Other confirmed records of this species are on the wild host plants of the genera Atylosia and Rhynchosia at ICRISAT Hyderabad, India. Spencer (1973; 1977) has listed Cajanus indicus Spreng; Flemingia sp. and Phaseolus radiatus Linn. as leguminose hosts of this species.
Geographical distribution - The members of this species are known from Formosa, Australia, India,Nepal, Ceylon and Indonesia. I examined the following materials from Uttar Pardesh:

India: Uttar Pardesh : 4 o $^{\star}$ Pantnagar, District Nainital, from pods of Cajanus cajan (Linn. ) Millsp., Coll. 29.iv.87, emerged 8-19.xii.87; 2 o $0^{*}$ same locality and host, Coll. 12. xii. 87, emerged 1922.xii. 87; 3 to $^{-}$Jeolikot at an elevation of 4000 feet from Pantnagar, from pods of Flemingia congesta Roxb., Coll. 13. i.88, emerged 22- 23.i.88. 


\section{Acknowledgements}

Thanks are due to Dr.P.K. Pathak and Dr. V.K. Sehgal, Professors, Department of Entomology, College of Agriculture, G.B. Pant University of Agriculture and Technology, Nainital, Uttaranchal, India. Further, author is indebted to University Grants Commisions, India and Tribhuvan University, Nepal for providing fellowship to carry this research at that University. Thanks are also due to Dr. Gour and his associates, Forest Research Institute, Dehradun for identification of various hosts plants.

\section{References}

Poudyal, B. 2003. Species determination and some ecological studies of agromyzid flies associated with some commonly cultivated leguminous crops of Jhapa district, Eastern Nepal. Dept. of Zoology, P.G. Campus, T.U., Biratnagar. 87p. (M.Sc. Thesis).

Frick, K.E. 1952. A generic revision of the family Agromyzidae (Diptera) with a catalogue of new world species. Univ. Calif. Publs. Ent., 8(8): 339452.

Ipe, M. Ipe.1967. A detailed morphological study of the external and internal genital organs of male Melanagromyza obtusa ( Malloch ), a pest of Cajanus indicus L. Agromyzidae : Diptera. Indian J. Ent. 29(1): 1-10.

Ipe M. Ipe. 1987. Biosystematic studies on Agromyzidae from India. Proceedings of the Indian Academy of Sciences, Animal Sciences 96(5): 573-581.

Spencer, K.A. 1963a. Insects of Micronesia Diptera Agromyzidae. Insects of Micronesia.14(5):135162.

Spencer, K.A. 1963b. The Australian Agromyzidae (Diptera, Insecta). Rec. Aust. Mus. 15: 305-354.

Spencer, K.A. 1973. Agromyzidae (Diptera) of economic importance. Ser. Entomol.9: 1-405.

Spencer, K.A. 1977. Notes on world Agromyzidae, with the description of 16 new Species (Diptera: Agromyzidae). Beitr. Ent. 27(2): 233-245.

Sehgal, V.K.1965. Studies on Indian Agromyzidae (Diptera). Beitr . Ent .15: 3-10.
Sehgal, V.K.1987. Agromyzidae (Diptera) of Economic Importance in India and their Management. In: Recent Advances in Entomology (Eds. Y.K. Mathur et al., Gopal Prakashan, Kanpur, India. pp. 111-140

Spencer, K.A. and G.C. Steyskal.1986. Manual of the Agromyzidae (Diptera) of the United States U.S.A., U.S. Department of Agriculture, Agriculture hand book No. 638, 478p.

Santokh Singh and Ipe M. Ipe. 1973. Agromyzidae from India. Mem. Sch. Ent.1. 266p.

Santokh Singh, 1982. Ecology of the Agromyzidae (Diptera) associated with Leguminous crops in India. Mem. Sch. Ent. 8,126 p.

Thapa, Moon. 2005. Study of field population and diversity of Leaf miners (Diptera: Agromyzidae ) infesting Mung bean Vigna radiata (Linn.) Wilczek grown in Biratnagar eastern Nepal. M.Sc.Thesis, Dept. of Zoology, Post Graduate Campus, Biratnagar, T.U. Nepal. 226p.

Thapa Moon. 2006. Study on Species diversity and proportion of leaf miners (Diptera: Agromyzidae) associated with Vigna radiate (Linn.) Wilczek. In Natural Resource Management (Eds. S.B. Karmacharya, M.R. Dhakal,S.N. Jha, T.N Mandal, M.K. Chettri, B.R. Subba, U. Koirala, B. Niroula and K.P. Limbu). PG Campus (Biratnagar), Nepal Biological Society and Ecological Society (ECOS), pp.464-465.

Thapa, Moon. 2012. Comparison of population of Melanagromyza sojae and Liriomyza sativae associated with Mung bean Vigna radiate (Linn.) Wilczek grown in Biratnagar, eastern Nepal. Nepalese Journal of Biosciences 2: 154-155.

Thapa, R.B. 1991. Survey and taxonomic studies on the Agromyzid flies associated with leguminious hosts at Pantnagar in the northen India.G.B. Pant University of Agriculture and Technology, Pantnagar, India. 420p. (Ph.D. Thesis)

Thapa, R.B. 1996. Survey of Agromyzid flies (Leaf miners) associated with economically important crops and weeds in and around Biratnagar, Eastern Nepal, Research report Research Division, T.U. Kirtipur, (1995-1996), Nepal, 16p.

Thapa, R.B. 1997a. Survey of agromyzid flies (Leaf miners) associated with economically important crops and weed in and around Biratnagar, eastern, Nepal. Report, Research Divison, Tribhuvan University, Kirtipur. 15p. 
Ram Bahadur Thapa / Our Nature (2012) 10: 258-268

Thapa, R.B.1997b. Legume Host Plants and the Agromyzid Species from Pantnagar District (Nainital) Utter Pradesh, India. In: Proceedings of II $^{\text {nd }}$ National Conference on Science and Technology, Kathmandu, 8-11 June 1994. Royal Nepal Academy of Science and Technology, pp.100-105.

Thapa, R.B. 2000. Survey of agromyzid host range in Morang district, eastern Nepal. Report, UGC, Nepal.

Thapa, R.B.2006. Survey of Agromyzid host range in Morang district, eastern Nepal. In Natural Resource Management (Eds. S.B. Karmacharya,
M.R. Dhakal,S.N. Jha, T.N. Mandal, M.K. Chettri, B.R. Subba, U. Koirala, B. Niroula and K.P. Limbu). PG Campus (Biratnagar), Nepal Biological Society and Ecological Society (ECOS), pp. 231-238

Thapa, R.B. 2011. Description of new species of leaf miners (Diptera, Agromyzidae) associated with leguminous host described from northern India. Nepalese Journal of Biosciences 1: 66-82.

Thapa, R.B. 2012. Redescription of Melanagromyza sojae (Zehntner) from India and Nepal. Nepalese Journal of Biosciences 2: 64-70. 